University of South Carolina

Scholar Commons

\title{
Correlates of Physical Activity in Black, Hispanic, and White Middle School Girls
}

\author{
Evelyn B. Kelly \\ Deborah Parra-Medina \\ Karin A. Pfeiffer \\ Marsha Dowda \\ University of South Carolina - Columbia, mdowda@mailbox.sc.edu \\ Terry L. Conway
}

See next page for additional authors

Follow this and additional works at: https://scholarcommons.sc.edu/

sph_physical_activity_public_health_facpub

Part of the Public Health Commons

\section{Publication Info}

Published in Journal of Physical Activity and Health, Volume 7, Issue 2, 2010, pages 184-193.

Kelly, E. B., Parra-Medina, D., Pfeiffer, K. A., Dowda, M., Conway, T. L., Webber, L. S., ... Pate, R. R. (2010). Correlates of physical activity in black, Hispanic, and white middle school girls. Journal of Physical Activity and Health, 7(2),184-193.

(c) Journal of Physical Activity and Health, 2010, Human Kinetics

This Article is brought to you by the Physical Activity and Public Health at Scholar Commons. It has been accepted for inclusion in Faculty Publications by an authorized administrator of Scholar Commons. For more information, please contact digres@mailbox.sc.edu. 


\section{Author(s)}

Evelyn B. Kelly, Deborah Parra-Medina, Karin A. Pfeiffer, Marsha Dowda, Terry L. Conway, Larry S. Webber, Jared B. Jobe, Scott Going, and Russell R. Pate 


\title{
Correlates of Physical Activity in Black, Hispanic, and White Middle School Girls
}

\section{Evelyn B. Kelly, Deborah Parra-Medina, Karin A. Pfeiffer, Marsha Dowda, Terry L. Conway, Larry S. Webber, Jared B. Jobe, Scott Going, and Russell R. Pate}

\begin{abstract}
Background: A need exists to better understand multilevel influences on physical activity among diverse samples of girls. This study examined correlates of moderate-to-vigorous physical activity (MVPA) among adolescent girls from different racial/ethnic backgrounds. Methods: 1,180 6th grade girls (24.5\% black, $15.7 \%$ Hispanic, and 59.8\% white) completed a supervised self-administered questionnaire that measured hypothesized correlates of PA. MVPA data were collected for 6 days using the ActiGraph accelerometer. Hierarchical regression analysis was used to examine correlates of PA in each racial/ethnic group. Results: Hispanic girls $(n=185)$ engaged in 21.7 minutes of MVPA per day, black girls $(n=289)$ engaged in 19.5 minutes of MVPA per day, and white girls $(\mathrm{n}=706)$ engaged in 22.8 minutes of MVPA per day. Perceived transportation barriers $(+; P=.010)$ were significantly and positively related to MVPA for Hispanic girls. For black girls, Body Mass Index $(\mathrm{BMI})(-; P=.005)$ and social support from friends $(+; P=.006)$ were significant correlates of MVPA. For white girls, BMI $(-; P<.001)$, barriers $(-; P=.012)$, social support from friends $(+; P=.010)$, participation in school sports $(+; P=.009)$, and community sports $(+; P=.025)$ were significant correlates of MVPA. Explained variance ranged from 30\% to 35\%. Conclusions: Correlates of MVPA varied by racial/ ethnic groups. Effective interventions in ethnically diverse populations may require culturally tailored strategies.
\end{abstract}

Keywords: black, Hispanic, white, race/ethnicity analysis, accelerometry

Engaging in regular physical activity is beneficial to the health and well-being of children and adolescents. ${ }^{1}$ Despite the well-known benefits of physical activity, ${ }^{1}$ many youth fail to meet current physical activity guidelines. According to the 2005 Youth Risk Behavior Surveillance Survey, only $35.8 \%$ of high school students (9th-12th grade) met the recommended standard of engaging in at least 60 minutes of moderate intensity physical activity on most days of the week, preferably daily. ${ }^{2}$ Physical activity levels are lower in girls than boys, with $27.8 \%$ of girls versus $43.8 \%$ of boys meeting that guideline. ${ }^{2}$ Moreover, the prevalence of physical

Kelly and Dowda are with the Arnold School of Public Health, University of South Carolina, Columbia, SC. Parra-Medina is with the Institute for Health Promotion Research, The University of Texas Health Science Center at San Antonio, Texas. Pfeiffer is with the Dept of Kinesiology, Michigan State University, East Lansing, MI. Conway is with the Dept of Public Health, San Diego State University, San Diego, CA. Webber is with the Dept of Biostatistics, Tulane University School of Public Health and Tropical Medicine, New Orleans, LA. Jobe is with the National Heart, Lung, and Blood Institute, Division of Epidemiology and Clinical Applications, Bethesda, MD. Going is with the Dept of Physiology and Nutritional Sciences, University of Arizona, Tucson, AZ. Pate is with the Dept of Exercise Science, University of South Carolina, Columbia, SC. activity is lowest in girls from racial and ethnic minority groups. Only $26 \%$ of Hispanic girls and $21.3 \%$ of black girls meet the recommended guideline, compared with $30.2 \%$ of white girls. ${ }^{2}$ Because a sharp decline in physical activity occurs during adolescence, particularly in girls, ${ }^{3}$ it is essential to develop programs that promote physical activity during this critical period.

To determine why racial/ethnic populations exhibit different physical activity patterns, it is important to investigate the psychosocial and environmental correlates that influence physical activity. A review of published research on the correlates of physical activity among children and adolescents conducted by Sallis et al (2000) identified several factors that were consistently associated with physical activity among children (ages 4 to 12), including a healthy diet, intention to be active, parental overweight status, perceived barriers, physical activity preferences, previous physical activity, program/ facility access, male gender, and time spent outdoors. ${ }^{4}$ Although a number of studies have included minorities, few have both examined the correlates of physical activity by race/ethnicity and included black, Hispanic, and white adolescent girls. One study found differences in psychosocial and physical environmental variables between 8th grade white and black girls. ${ }^{5}$ In addition, these studies have relied on self-report measures of PA, which have been shown to have limited validity, particularly among children. ${ }^{6,7}$ 
To understand the differences in physical activity behavior between girls from different racial/ethnic groups, it is important to examine the factors that influence physical activity in diverse samples of adolescent girls. Understanding these differences and the factors that underlie them can aid in the design of more effective, culturally competent interventions to increase physical activity, prevent weight gain, and eliminate health disparities. Accordingly, the purpose of this study was to examine the psychosocial and environmental correlates of moderate-to-vigorous physical activity (MVPA) and vigorous physical activity (VPA) among black, Hispanic, and white adolescent girls. This study was guided by a social-ecological model of health behavior. ${ }^{8}$

\section{Methods}

\section{Study Design}

The Trial of Activity in Adolescent Girls (TAAG) was a multicenter group-randomized trial sponsored by the National Heart, Lung, and Blood Institute (NHLBI). . $^{9110}$ The primary aim of TAAG was to determine whether interventions that link schools to community organizations reduce the age-related decline in moderate-to-vigorous physical activity (MVPA) in middle school girls. TAAG was a collaborative study involving 6 field centers (University of Arizona, San Diego State University, Tulane University, University of Minnesota, University of Maryland, and University of South Carolina), the coordinating center at the University of North Carolina, and the NHLBI. Data for the current cross-sectional investigation were collected as part of the baseline assessment administered to 6th grade girls who participated in the TAAG study. Data presented in this report were collected before schools were randomized to intervention or control groups.

\section{Participants}

Data collection methods were approved by the institutional review board at each participating university, including the coordinating center. Each girl's parent or guardian provided written informed consent, and all girls provided written assent before data collection. The targeted sample was $80 \%$ of a randomly selected group of 60 students at each of the 6 schools at each field center $(48$ girls $\times 36$ schools $=1728$ participants $)$. The field centers exceeded the recruitment goal and a total of 2198 girls (30.6\% black, $14.1 \%$ Hispanic, and $55.3 \%$ white) participated in the data collection. Girls who had missing accelerometer data were deleted, and a total of 1366 girls ( $26.1 \%$ black, $16.2 \%$ Hispanic, and $57.8 \%$ white; $\mathrm{BMI}=$ $20.8 \pm 4.9$; median MVPA $=21.7$ ) remained. After deletions for missing values for demographic and personal/ behavioral variables $(n=23)$, intrapersonal $(n=73)$, interpersonal $(\mathrm{n}=72)$, and community/environmental $(\mathrm{n}=18)$ variables, 1180 girls remained for data analysis (24.5\% black, $15.7 \%$ Hispanic, and $59.8 \%$ white; BMI $=20.7 \pm 4.8$; median MVPA $=21.9$ ).

\section{Measures}

\section{Physical Activity}

Moderate-to-vigorous physical activity (MVPA) and vigorous physical activity (VPA) were measured using the MTI ActiGraph (formerly Computer Sciences and Applications) uniaxial accelerometer. Each participant wore the monitor for 7 days, except at night while sleeping or during any water activity (eg, bathing, swimming). Although each participant wore the monitor for 7 days, data were collected for 6 days. The accelerometer was attached to a belt that was worn around the waist, with the accelerometer positioned on the participant's right hip. Accelerometer counts were recorded in 30-second time increments to appropriately reflect the activity level of adolescents. Accelerometer readings were processed using methods similar to those reported by Puyau et al. ${ }^{11}$ Readings above 1500 counts per half minute were treated as MVPA ${ }^{12}$ and counts above 2600 per half minutes were treated as VPA In the event that there were missing activity data, values were replaced via imputation based on the Expectation Maximization (EM) algorithm, which was developed by the TAAG investigators. ${ }^{13}$

\section{Body Mass Index (BMI)}

Trained data collectors assessed height and weight according to standardized procedures. All height and weight measures were taken with shoes off and the participant wearing light clothing. Height was measured 2 times to the nearest $0.1 \mathrm{~cm}$ using a portable stadiometer (Shorr Productions; Olney, MD). Weight was measured 2 times to the nearest $0.1 \mathrm{~kg}$ using a portable digital scale (Seca 880; Hanover, MD). If the 2 measures were $\geq 1.0 \mathrm{~cm}$ or $0.5 \mathrm{~kg}$ apart, a second set of 2 measures was taken. The average of each of the 2 measures was used to calculate BMI by dividing weight (kilograms) by height (meters) squared.

\section{Questionnaire}

A self-administered survey instrument, using a paper and pencil format, was administered in a classroom setting, during one 40- to 45-minute class period. The questionnaire was administered by trained data collectors who provided initial instruction, were available to answer questions, and oversaw the overall procedures of administration. The instrument included sections designed to measure hypothesized determinants of physical activity in youth, including demographic information. Constructs from the questionnaire were organized into 4 blocks: personal/behavioral, intrapersonal, interpersonal, and environmental factors. These categories were created in accordance with the social ecological framework guiding the TAAG intervention. ${ }^{8}$ Descriptions of the variables created to reflect each construct are presented in Table 1. The variables had acceptable consistency (Cronbach's alpha ranging from 0.67 to 0.90 ) and test-retest reliability (0.56 to 0.78$)$. 
Table 1 Description of Correlates of Adolescent Physical Activity

\begin{tabular}{|c|c|c|c|c|c|}
\hline Variable & Operational definition & $\begin{array}{l}\text { No. items } \\
\text { [range] }\end{array}$ & $\begin{array}{l}\text { Cronbach's } \\
\text { alpha }\end{array}$ & $\begin{array}{l}\text { Test-retest } \\
\text { reliability }\end{array}$ & References \\
\hline \multicolumn{6}{|l|}{ Intrapersonal } \\
\hline Perceived barriers & $\begin{array}{l}\text { Perceived Barriers; } 1=\text { Never, } 5=\text { Very } \\
\text { often }\end{array}$ & $10[1,5]$ & 0.79 & 0.77 & $\begin{array}{l}\text { Sallis }(2002)^{14} \\
\text { Motl }(2000)^{15}\end{array}$ \\
\hline Perceived benefits & $\begin{array}{l}\text { Perceived Benefits; } 1=\text { Disagree a lot, } \\
5=\text { Agree a lot }\end{array}$ & $9[1,5]$ & 0.80 & 0.64 & $\begin{array}{l}\text { Sallis }(2002)^{14} \\
\text { Motl }(2000)^{15}\end{array}$ \\
\hline $\begin{array}{l}\text { Enjoyment of } \\
\text { physical activity }\end{array}$ & $\begin{array}{l}\text { Enjoyment of Physical Activity; } 1=\text { Dis- } \\
\text { agree a lot, } 5=\text { Agree a lot; reverse scoring } \\
\text { of "unenjoyable" feelings when active }\end{array}$ & $7[1,5]$ & 0.90 & 0.73 & $\operatorname{Motl}(2001)^{16}$ \\
\hline Self-efficacy & $\begin{array}{l}\text { Self-efficacy } ; 1=\text { Disagree a lot, } \\
5=\text { Agree a lot }\end{array}$ & $8[1,5]$ & 0.80 & 0.78 & $\begin{array}{l}\text { Saunders }(1997)^{17} \\
\text { Motl }(2000)^{15}\end{array}$ \\
\hline \multicolumn{6}{|l|}{ Interpersonal } \\
\hline Family support & Family support; $1=$ None, $5=$ Every day & $5[1,5]$ & 0.81 & $\mathrm{n} / \mathrm{a}$ & Sallis $(2002)^{14}$ \\
\hline Friend support & $\begin{array}{l}\text { Social support from friends; } 1=\text { None, } \\
5 \text { = Every day }\end{array}$ & $3[1,5]$ & 0.79 & $\mathrm{n} / \mathrm{a}$ & Sallis $(2002)^{14}$ \\
\hline $\begin{array}{l}\text { Teacher climate at } \\
\text { school }\end{array}$ & $\begin{array}{l}\text { Teachers' behaviors "positive" for girls' } \\
\text { PA; } 1 \text { = Disagree a lot, } 5 \text { = Agree a lot; } \\
\text { Reverse scored so higher values indicate } \\
\text { more positive climate for girls' PA }\end{array}$ & $2[1,5]$ & 0.81 & 0.59 & $\begin{array}{l}\text { Birnbaum } \\
(2005)^{18}\end{array}$ \\
\hline $\begin{array}{l}\text { Boy climate at } \\
\text { school }\end{array}$ & $\begin{array}{l}\text { Boys' behaviors "positive" for girls' } \\
\text { PA; } 1 \text { = Disagree a lot, } 5=\text { Agree a lot; } \\
\text { Reverse scored so higher values indicate } \\
\text { more positive climate for girls' PA }\end{array}$ & $3[1,5]$ & 0.67 & 0.56 & $\begin{array}{l}\text { Birnbaum } \\
(2005)^{18}\end{array}$ \\
\hline \multicolumn{6}{|c|}{ Community/environmental } \\
\hline $\begin{array}{l}\text { Perceived transpor- } \\
\text { tation barriers }\end{array}$ & $\begin{array}{l}\text { Difficulty level in obtaining transporta- } \\
\text { tion home from after-school activities } \\
\text { (at school and in a location other than } \\
\text { school), and vice versa; } 1=\text { Not at all dif- } \\
\text { ficult, } 4=\text { Impossible }\end{array}$ & $3[1,4]$ & 0.73 & $\mathrm{n} / \mathrm{a}$ & $\mathrm{n} / \mathrm{a}$ \\
\hline
\end{tabular}

\section{Personal and Behavioral Variables}

Variables included in the personal and behavior block were: Age (years), Self-Reported Free/Reduced Lunch (yes, no, or don't know/missing), and scale scores reflecting the girl's participation in community sports, school sports, and physical activity classes/lessons outside of the school. Two of these scales, School Sports and Community Sports, were computed as the sum of a checklist $(0=$ no; $1=$ yes $)$ of 15 sports teams (including "other") that a girl could have participated in during the past year at school or outside of school (one checklist for each). The other scale, Sports and Activity Participation, was computed as the sum of 18 physical activity classes/lessons (including "other") that a girl could have participated in during the past year, outside of school.

\section{Intrapersonal Variables}

Measures included in the block of intrapersonal variables included perceived barriers to physical activity, perceived benefits of physical activity, enjoyment of physical activity, and self-efficacy for physical activity. The Perceived Barriers to PA scale was modified from the Amherst Health and Activity Study ${ }^{14}$ and was computed as the average of 10 statements answered using a 5-point neververy often (1-5) scale; barrier statements included reasons that could keep a person from being physically active (eg, bad weather, lack of time, lack of knowledge, not liking to sweat, embarrassment). The Perceived Benefits of PA scale was adapted both from the Benefits scale used in the Amherst Study ${ }^{14}$ and the Attitude Questionnaire, ${ }^{15}$ and was computed as the average of 9 statements answered using a 5-point disagree-agree (1-5) scale; benefit statements included positive outcomes from being physically active (eg, spend time with friends, keep in shape, put in good mood, be fun, look better, feel good about self).

The Enjoyment of Physical Activity scale was computed as the average of responses on a 5-point disagreeagree (1-5) scale for 7 statements related inversely to "enjoyment" of PA. ${ }^{16}$ The items reflect negative feelings experienced when being physically active (eg, feel bored, dislike being active, feel frustrated, have no fun, not interesting, depressing, rather be doing something else), which were reverse scored so that higher scale scores reflected more positive feelings or "enjoyment" while being physically active.

The Self-Efficacy for PA scale was measured with a subset of items from a previously validated scale ${ }^{17}$ found to form a reliable factor with 8 items. ${ }^{15}$ The scale was computed as the average of 8 statements, answered using a 5-point disagree-agree (1-5) scale that reflected a girl's confidence in her ability to find ways to be physically active on most days (eg, I can be physically active during my free time on most days even if it is very hot or cold outside). 


\section{Interpersonal Variables}

Measures included in the block of interpersonal variables were 2 social support scales (family support and friend support) and 2 school climate scales (teacher-related and boy-related) regarding girls' physical activity.

Social Support. The parent and peer social support scales were originally developed for the Amherst Health and Activity Study. ${ }^{14}$ For the TAAG study, 5 items were averaged to form the Family Support scale (family members encouraged PA, did PA with girl, provided transportation for PA, watched girl do PA, and told girl she's doing well in PA). Three items were averaged to form the Friend Support scale (friends encouraged girl's PA, friends do PA with girl, friends tell girl she's doing well in PA). All the social support items were answered using a 5-point scale (none, once, sometimes, almost every day, or every day).

School Climate. In a TAAG pilot study, Birnbaum et $\mathrm{al}^{18}$ used confirmatory factor analysis to develop 2 scales that assess perceived school climate related to girls' physical activity: (a) perceptions about teachers' behavior (Teacher Climate) and (b) perceptions about boys' behavior (Boy Climate) in relation to girls' PA. Items were answered using a 5-point agree-disagree scale $(1=$ disagree a lot, 5 = agree a lot $)$, and responses were recoded so that higher scale scores indicated a more "positive climate" for girls' PA. Two items were averaged to form the Teacher Climate scale (eg, "PE teachers act like they think it is more important for boys to be physically active than girls," and "most other teachers act like they think it is more important for boys to be physically active than girls"). Three items were averaged to form the Boy Climate scale (eg, "boys make rude comments around girls who are being physically active," "being physically active around boys makes me uncomfortable," "boys stare too much at girls who are being physically active").

\section{Community/Environmental Variables}

Measures included in the block of Community/Environmental variables were (a) School-level Socio-Economic Status, as indicated by the percent of children enrolled in the school who receive free/reduced lunch, and (b) Perceived Transportation Barriers related to participating in after-school activities (eg, getting home afterward from school, getting to an activity somewhere other than school, and getting home from an activity somewhere other than school). These questions were created specifically for the TAAG study. Girls rated after-school transportation difficulty on a 4-point rating scale (not at all difficult, somewhat difficult, very difficult, impossible), and the scale score was the mean of the 3 items.

\section{Statistical Analysis}

Means and standard deviations were calculated for the physical activity, personal and behavioral, intrapersonal, interpersonal, and community/environmental variables by race/ethnic group. In addition, mixed model ANOVA was performed to determine whether there were differences among the 3 racial/ethnic groups. Since both MVPA and VPA were skewed, data for these variables were log transformed for all analyses. Product moment correlations were calculated between potential PA correlates and MVPA and VPA by race/ethnic group. Correlations between potential correlates were assessed and indicated that multicollinearity was not an issue. Differences in the magnitudes of the correlation coefficients between either MVPA or VPA and the various personal, intrapersonal, interpersonal, and community/environmental variables for the 3 groups were compared using a test of homogeneity among 2 or more correlation coefficents. ${ }^{19}$ Essentially, the weighted sum of squares of the z-values corresponding to correlation coefficients were calculated.

Personal and potential PA variables that were bivariately correlated with MVPA or VPA $(P<.10)$ were added in blocks to models separately for each race/ethnic group. After addition of each block of variables (personal, intrapersonal, interpersonal, then community/environmental), a mixed model concordance correlation coefficient corresponding to an $\mathrm{R}^{2}$ was calculated. ${ }^{20}$ The 4 blocks were entered into regressions in a standard order for each racial/ ethnic group. Personal variables were entered first to adjust for nonmodifiable correlates, so the models indicated whether other variables explained variance above that explained by demographics. Age, BMI, and self-reported free or reduced lunch were controlled for among the 3 groups. Intrapersonal variables were entered second because many interventions focus on changing psychological mediators. Interpersonal variables were entered third because few interventions have focused on modifying family and other social mediators, and community/ environmental variables were entered last. Variables that entered into regressions remained in the model throughout the addition of each block. Significance was set at the 0.05 level. Unstandardized beta coefficients and p-values are presented for the last model. Because MVPA and VPA were $\log$ transformed for the analyses, the beta coefficients can be interpreted as percent change in the dependent variable. Proc Mixed in SAS (version 9.1) was used to adjust for group clustering. Girls were nested within schools and schools were nested within the study site. Schools nested in the site were treated as a random variable.

\section{Results}

The means and standard deviations for demographic variables and other study variables and the percentages of self-reported free/reduced lunch and school socioeconomic status are presented in Table 2 for each of the 3 racial/ethnic groups. Since the means of the MVPA and VPA levels were skewed, median values were calculated. The median value for MVPA was 19.5 minutes per day for black girls, 21.7 minutes per day for Hispanic girls, and 22.8 minutes per day for white girls. For VPA, the median value was 4.2 minutes for black girls, 4.5 minutes for Hispanic girls, and 4.7 for white girls. Results from the mixed model ANOVA indicated significant differences 
Table 2 Characteristics by Race

\begin{tabular}{|c|c|c|c|c|}
\hline & Hispanic $(n=185)$ & Black $(n=289)$ & White $(n=706)$ & \\
\hline Variable & Mean (SD)/\% & Mean (SD)/\% & Mean (SD)/\% & $P$-value \\
\hline \multicolumn{5}{|l|}{ Personal and behavioral factors } \\
\hline Age & $11.9(0.5)$ & $12.1(0.7)$ & $11.9(0.4)$ & 0.070 \\
\hline $\mathrm{BMI}^{\mathrm{a}}$ & $22.3(5.6)$ & $22.1(5.5)$ & $19.7(4.0)$ & $<0.001$ \\
\hline Self reported free/reduced lunch & $62.1 \%$ & $67.8 \%$ & $20.7 \%$ & $<0.001$ \\
\hline Community sports & $1.8(2.6)$ & $2.5(3.0)$ & $2.1(1.7)$ & 0.140 \\
\hline School sports & $0.9(1.4)$ & $1.0(1.8)$ & $0.9(1.5)$ & 0.450 \\
\hline Sports/activity participation history ${ }^{b}$ & $1.6(2.1)$ & $2.3(2.7)$ & $2.1(1.8)$ & 0.020 \\
\hline \multicolumn{5}{|l|}{ Intrapersonal } \\
\hline Perceived barriers ${ }^{c}$ & $20.5(6.8)$ & $21.0(6.5)$ & $19.6(5.9)$ & 0.020 \\
\hline Perceived benefits ${ }^{\mathrm{d}}$ & $37.3(6.2)$ & $35.1(7.1)$ & $37.1(5.7)$ & 0.010 \\
\hline Enjoyment of physical activity ${ }^{e}$ & $29.2(6.6)$ & $29.3(6.1)$ & $31.2(5.1)$ & $<0.001$ \\
\hline Self-efficacy ${ }^{\mathrm{e}}$ & $28.3(7.0)$ & $28.3(6.6)$ & $30.5(5.9)$ & $<0.001$ \\
\hline \multicolumn{5}{|l|}{ Interpersonal } \\
\hline Family support ${ }^{\mathrm{e}}$ & $16.0(4.3)$ & $16.2(4.7)$ & $17.7(4.2)$ & 0.001 \\
\hline Friend support & $9.2(3.1)$ & $8.7(3.1)$ & $9.2(2.6)$ & 0.070 \\
\hline School climate (boys) ${ }^{\mathrm{e}}$ & $9.0(3.4)$ & $8.9(3.5)$ & $10.6(3.1)$ & 0.001 \\
\hline School climate (teachers) ${ }^{\mathrm{e}}$ & $7.9(2.3)$ & $7.3(2.7)$ & $8.1(2.2)$ & 0.003 \\
\hline \multicolumn{5}{|l|}{ Community/environment } \\
\hline Perceived transportation barriers & $5.2(2.0)$ & $5.0(2.0)$ & $5.0(1.7)$ & 0.290 \\
\hline School socio economic status ${ }^{\mathrm{f}}$ & $54.6 \%$ & $60.6 \%$ & $21.4 \%$ & $<0.001$ \\
\hline \multicolumn{5}{|l|}{ Activity levels (accelerometer) } \\
\hline MVPA minutes per day & & & & 0.100 \\
\hline Median & 21.7 & 19.5 & 22.8 & \\
\hline 10th percentile & 11.1 & 10.1 & 12.6 & \\
\hline 90th percentile & 40.1 & 39.7 & 41.3 & \\
\hline VPA minutes per day & & & & 0.230 \\
\hline Median & 4.5 & 4.2 & 4.7 & \\
\hline 10th percentile & 1.9 & 1.7 & 1.7 & \\
\hline 90th percentile & 10.6 & 12.1 & 11.7 & \\
\hline
\end{tabular}

Abbreviations: SD, Standard Deviation.

${ }^{a}$ White girls < Black or Hispanic girls.

${ }^{\mathrm{b}}$ Hispanic girls $<$ White or Black girls.

${ }^{c}$ White girls $<$ Black girls.

${ }^{\mathrm{d}}$ Black girls $<$ White or Hispanic girls.

${ }^{\mathrm{e}}$ White girls $>$ than Black or Hispanic girls.

${ }^{\mathrm{f}}$ All race groups differ.

among the 3 racial/ethnic groups. White girls had the lowest means for BMI, self-reported free or reduced lunch, and home alone, and were statistically different than black or Hispanic girls. They also had the highest mean of enjoyment of physical activity and self-efficacy and were statistically different than black or Hispanic girls. For the variable school socioeconomic status the differences between the $3 \mathrm{racial} / \mathrm{ethnic}$ groups were statistically significant, with white girls attending schools with a lower percent of students receiving free/reduced lunch, and black girls attending schools with the highest percent.

Table 3 shows the correlation coefficients of MVPA and VPA and 16 potential correlates for each racial/ethnic group. Factors that were significantly related among Hispanic girls for both levels of PA were self-efficacy $(+)$, family support (+), and friend support (+). Perceived transportation barriers (+) was significant for MVPA only, and school sports (+) and enjoyment of physical activity $(+)$ were significant for VPA only. Among black girls, age $(-)$, BMI (-), and social support from friends (+) were significant for both levels of physical activity. School climate from boys (-) was significant for MVPA and family support $(+)$ and school climate from teachers $(-)$ were significant for VPA. Factors that were not significantly related to MVPA and VPA for white girls included age, perceived benefits, school climate for boys, home alone, and school climate for teachers. The race comparison analysis (Table 3 ) indicated that there were significant differences between whites and the other 2 racial/ethnic groups for various personal factors (community sports, school sports, sports/ activity participation history, and age), perceived barriers, and transportation barriers. Table 4 shows the results of the 


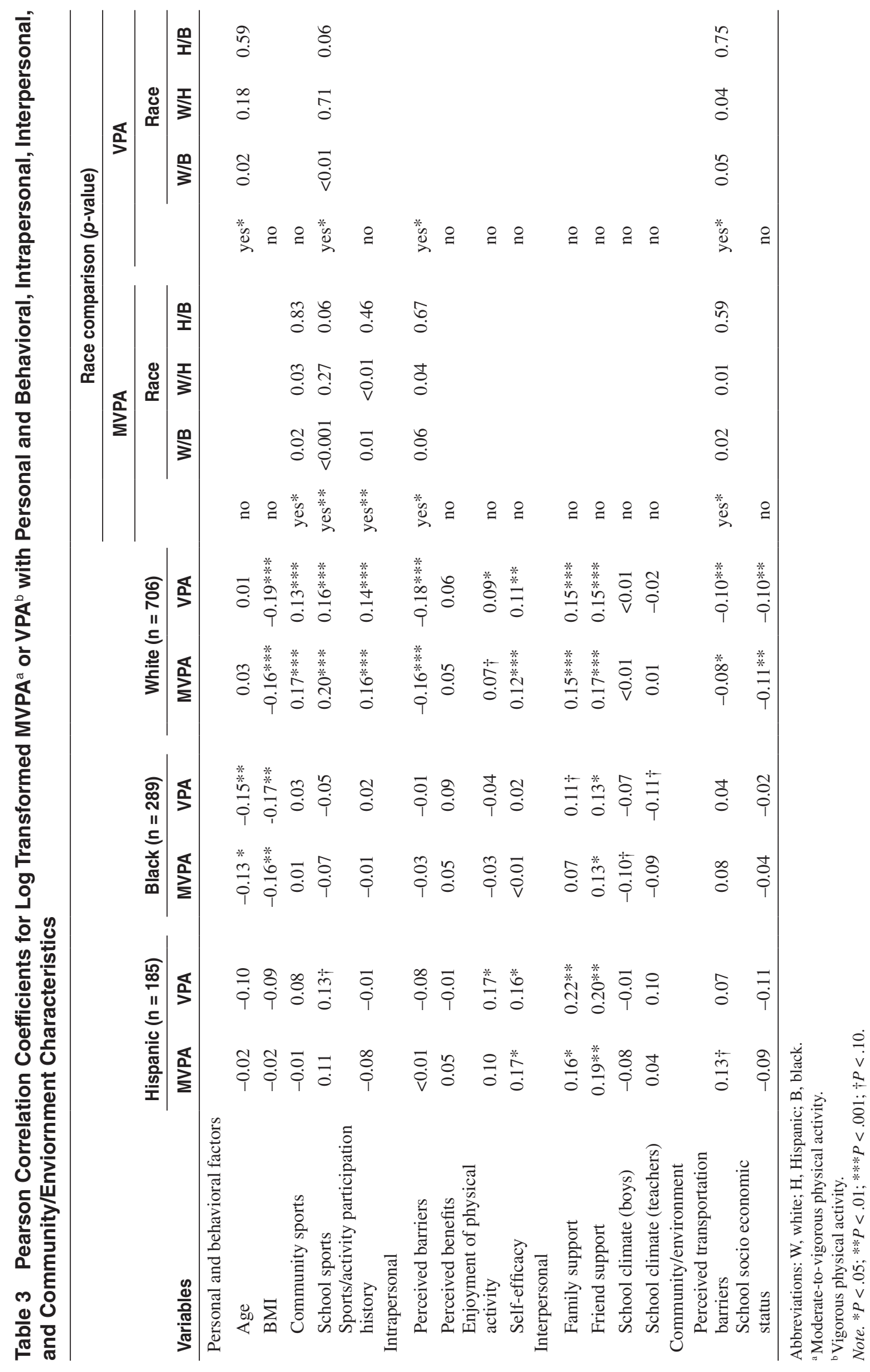




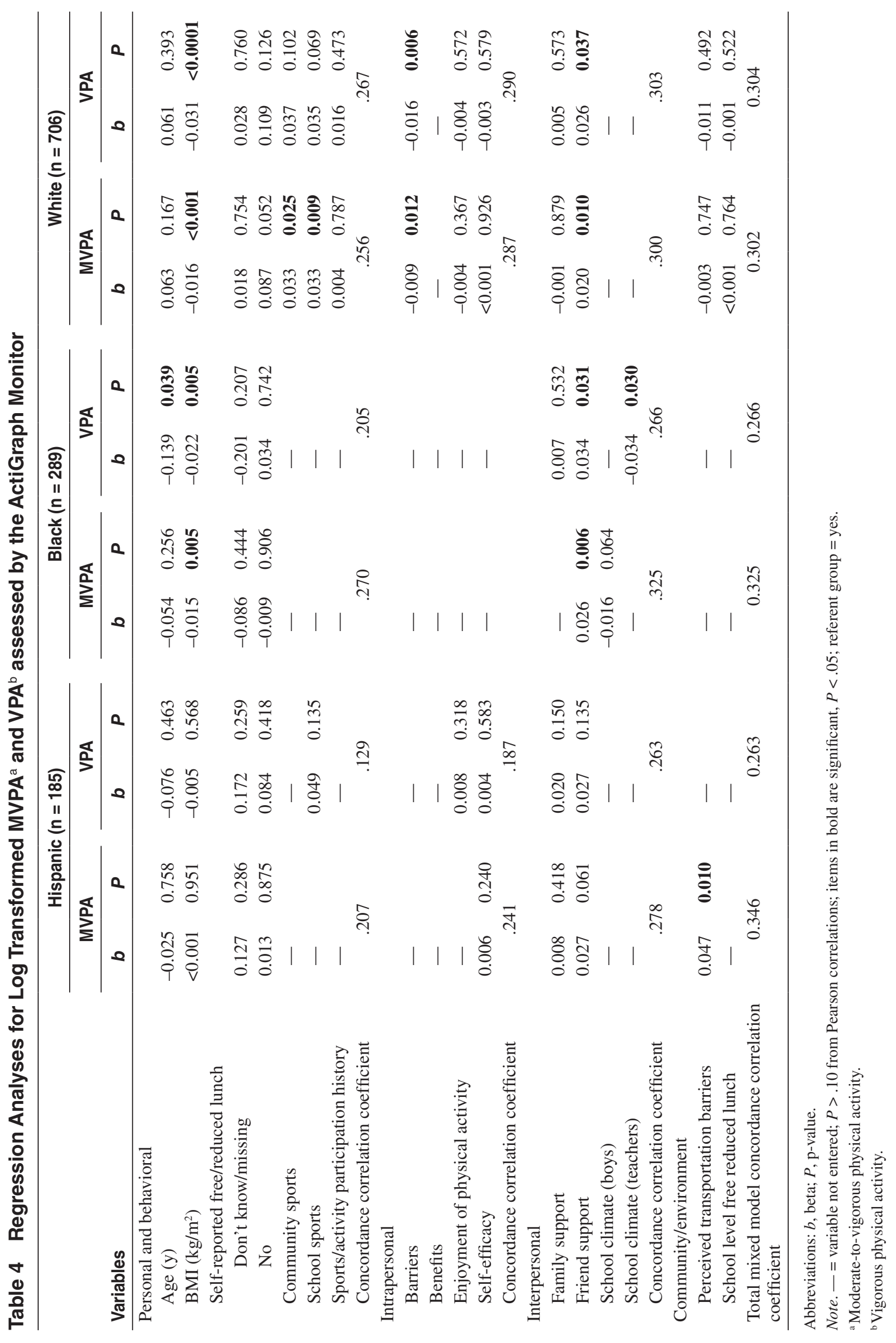


regression analyses for MVPA and VPA. Personal variables explained from $13 \%$ to $27 \%$ of the variance in the models. For Hispanic girls, after the 4 blocks of variables were added, perceived transportation barriers was significantly related to MVPA. For black girls, BMI, and social support from friends were significant. For white girls, BMI, community sports, schools sports, barriers, and social support from friends were significant. Explained variance for MVPA ranged from $30.2 \%$ to $34.6 \%$. For VPA, age, BMI, social support from friends, and school climate (teachers) were significant for black girls. For white girls, BMI, barriers, and social support from friends were significant. Explained variance for VPA ranged from $26.3 \%$ to $30.4 \%$.

\section{Discussion}

Identifying correlates of physical activity among subgroups of adolescent girls in the same study is important because such information could inform intervention efforts. The current study is unique because it used the same measures and protocols to compare multiple correlates of PA, which included personal, intrapersonal, interpersonal, and community/environmental correlates among black, Hispanic, and white adolescent girls. In addition, we used accelerometry to assess MVPA and VPA levels. To our knowledge, this is the first study to analyze the same correlates among $3 \mathrm{racial} / \mathrm{ethnic}$ groups using an objective measure of physical activity. One of the most notable results was that different correlates were significantly related to MVPA and VPA across the 3 racial/ethnic groups. In bivariate analyses significant variables were found in all categories of correlates (personal/behavioral, intrapersonal, interpersonal, community/environment), supporting an interpretation that physical activity among adolescent girls is a complex behavior determined by multiple factors. This finding also supports an ecological model of behavior that conceives behavioral influences from personal, social, and environmental factors. Only "friend support" was consistently associated with physical activity in all subgroups and for both MVPA and VPA. This implies that social support/ social modeling interventions may be very important for promoting physical activity among all subgroups of girls in this age group. Few variables were significant in multivariate analyses and no single factor was significant in all subgroups. The implication is that interventions must target variables from all categories to achieve behavior change and may need to target specific variables in different race/ethnic groups.

The relationship between body weight variables and physical activity was different among subgroups of girls. Among black and white girls, BMI had an inverse relationship with both MVPA and VPA; however, no relationship was observed for Hispanic girls. Biddle et al conducted a systematic review of correlates among adolescent girls and found that increased BMI was negatively related to PA with a small effect size. ${ }^{21}$ Unlike the current study, none of the articles reviewed by Biddle et al used an objective physical activity measure. A recent TAAG study examined the relationships of body composition (both fat and fat-free mass components) with objectively measured physical activity. The study found significant inverse relationships with fat mass and fat-free mass and MVPA and VPA. ${ }^{22}$

In the multivariate analyses, social support from friends was significant among black and white girls for MVPA and VPA; it was significant for all subgroups in bivariate analyses. Previous reviews of correlates of physical activity among adolescents ${ }^{4,21}$ have found that the literature on social support from friends or peers is inconclusive. Reasons for the inconsistent findings include lack of reliability and validity of measures, different measures of physical activity, ${ }^{23}$ and the lack of clarity in defining and measuring the constructs of social support. ${ }^{24}$ Prochaska et al conducted a study to determine if the association between social support and physical activity varied when different methods of assessing physical activity in adolescents were used. The study found that the relationship between self-reported physical activity and peer support was significant, while the association between objective monitoring (accelerometer) of physical activity and peer support from friends was not significant. ${ }^{23}$ The extent to which the school climate supports girls' being physically active also may be important. School climate includes the physical environment (adequate facilities), social systems (interpersonal relationships that are respectful of gender differences and social development), cultural standards and gender role expectations (values and norms that support a physically active lifestyle for girls), and aggregated characteristics of the members of the school community (the prevalence of PA among girls in the school). Among black girls, school climate and social support from friends predicted vigorous physical activity, yet girls in this subgroup rated their school climate to be least supportive (Table 2). This finding suggests that interventions should encourage friends being active together and adult support of a physically active lifestyle for this subgroup of girls.

Compared with white girls in TAAG, Hispanic girls were less likely to participate in classes or sports teams outside of school and more likely to report transportation barriers. In fact, in the regression analyses, perceived transportation barriers were the only significant predictor of MVPA for Hispanic girls. Perceived difficultly of obtaining transportation was associated with higher levels of physical activity. In a previous TAAG analysis, walking for transportation before and after school was examined and, although no significant differences in frequency were noted by race/ethnicity, Hispanic girls reported the highest percentage of walking for transportation before and after school. ${ }^{25}$ This may indicate that Hispanic girls are receiving their PA by walking for transportation to and from school or engaging in other forms of physical activities while at home, such as household chores. Brownson et al described the patterns of physical activity among a diverse sample of women, and found that housework activity was the most common source of activity among Hispanic women. ${ }^{26}$ Hispanic girls in the current study 
also reported the lowest levels of community sports and sport/activity participation history. Perceived transportation barriers may affect Hispanic girls' ability to access school-based and community-based physical activity opportunities. Instrumental support from adults is important since most youth need adult assistance to participate (eg, fees, equipment, transportation). This population specific profile indicates that interventions that target MVPA in this population must address transportation barriers and instrumental support.

This investigation has several limitations, including the cross-sectional design of the study, which precluded inferring causal relationships between correlates and physical activity behavior. Another limitation was the comparison of self-reported correlates to an objective measure of physical activity. Previous studies that examined physical activity correlates have found the associations to vary depending on the instrument used to assess physical activity. ${ }^{23,27,28}$ Correlates identified in studies that used objective measures of PA have been found to be weaker or even nonsignificant compared with studies that used self-reported measures. One possible reason for the higher levels of variance or stronger associations between determinant variables and self-reported physical activity may be shared method variance. ${ }^{23,28}$ Future studies examining correlates of physical activity should consider using both self-reported and objective measures of physical activity. Despite this limitation, the findings of this study contribute new information to the literature regarding correlates of physical activity among adolescents.

An additional limitation of the study was that no data were collected on the country of origin or level of acculturation among Hispanic girls. This limits the generalizability of the results. Health behavior differences exist between Hispanics/Latinos born in the United States and those who are foreign-born, and these differences may affect physical activity levels. Moreover, Hispanics and other minority groups are not homogeneous and differences may exist among Hispanic groups born in the United States. Gordon-Larsen et al found that among Cuban and Mexican adolescents, inactivity and low levels of physical activity increased with generation of US residence. ${ }^{29}$ Future studies should take into consideration the country of origin and acculturation status, and include a large sample of Hispanics.

Based on the results of this study, several conclusions and recommendations can be made regarding the psychosocial and environmental correlates of physical activity in adolescent girls. Although there is a significant amount of literature on the correlates of physical activity in adolescent girls, few studies include a diverse sample and conduct race/ethnicity analyses. Race/ ethnicity analyses will allow meaningful conclusions to be made about the relationship between variables and physical activity among different populations. In addition, the differences in correlates that were significantly related to activity levels among the 3 racial/ ethnic groups suggest a need to develop culturally tailored physical activity programs that provide a range of extracurricular and community activities that meet the interests and needs of various populations of adolescent girls.

\section{Acknowledgments}

This study was funded by a grant from the National Institutes of Health (3U01HL066852-06S2). We would like to thank the study sites (University of Arizona, San Diego State University, Tulane University, University of Minnesota, University of Maryland, University of South Carolina and University of North Carolina at Chapel Hill) for their collaboration and efforts. We thank Gaye Groover Christmus, MPH, for editing the manuscript.

\section{References}

1. Strong WB, Malina RM, Blimkie CJ, et al. Evidence based physical activity for school-age youth. J Pediatr. 2005;146(6):732-737.

2. Centers for Disease Control and Prevention. Youth Risk Behavior Surveillance-United States, 2005. MMWR Morb Mortal Wkly Rep. 2006;55(SS05):1-112.

3. Kimm SY, Glynn NW, Kriska AM, et al. Longitudinal changes in physical activity in a biracial cohort during adolescence. Med Sci Sports Exerc. 2000;32(8):1445-1454.

4. Sallis JF, Prochaska JJ, Taylor WC. A review of correlates of physical activity of children and adolescents. Med Sci Sports Exerc. 2000;32(5):963-975.

5. Felton GM, Dowda M, Ward DS, et al. Differences in physical activity between black and white girls living in rural and urban areas. J Sch Health. 2002;72:250-255.

6. Pate RR. Physical activity assessment in children and adolescents. Crit Rev Food Sci Nutr. 1993;33(4):321-326.

7. Freedson PS. Electronic motion sensors and heart rate as measures of physical activity in children. J Sch Health. 1991;61(5):215-219.

8. Elder JP, Lytle L, Sallis JF, et al. A description of the social-ecological framework used in the Trial of Activity for Adolescent Girls (TAAG). Health Educ Res. 2007;22(2):155-165.

9. Stevens J, Murray DM, Catellier DJ, et al. Design of the Trial of Activity in Adolescent Girls (TAAG). Contemp Clin Trials. 2005;26(2):223-233.

10. Webber LS, Catellier DJ, Lytle LA, et al. Promoting physical activity in middle-school girls: Trial of Activity for Adolescent Girls. Am J Prev Med. 2008;34(3):173-184.

11. Puyau MR, Adolph AL, Vohra FA, Butte NF. Validation and calibration of physical activity monitors in children. Obes Res. 2002;10(3):150-157.

12. Treuth MS, Schmitz K, Catellier DJ, et al. Defining accelerometer thresholds for activity intensities in adolescent girls. Med Sci Sports Exerc. 2004;36(7):1259-1266.

13. Catellier DJ, Hannan PJ, Murray DM et al. Imputation of missing data when measuring physical activity by accelerometry. Med Sci Sports Exerc. 2005;37(11 Suppl):S555S562.

14. Sallis JF, Taylor WC, Dowda M, Freedson PS, Pate RR. Correlates of vigorous physical activity for children in grades 1 through 12: Comparing parent-reported and objectively measured physical activity. Pediatr Exerc Sci. 2002;14(1):30-44. 
15. Motl RW, Dishman RK, Trost SG, et al. Factorial validity and invariance of questionnaires measuring socialcognitive determinants of physical activity among adolescent girls. Prev Med. 2000;31:584-594.

16. Motl RW, Dishman RK, Saunders R, Dowda M, Felton G, Pate RR. Measuring enjoyment of physical activity in adolescent girls. Am J Prev Med. 2001;21(2):110-117.

17. Saunders RP, Pate RR, Felton GM, et al. Development of questionnaires to measure psychosocial influences on children's physical activity. Prev Med. 1997;26(241):247.

18. Birnbaum AS, Evenson KR, Motl RW, et al. Scale development for perceived school climate for girls' physical activity. Am J Health Behav. 2005;29(3):250-257.

19. Sokal RR, Rohlf JF. Biometry: The Principles and Practice of Statistics in Biological Research. 3rd ed. New York: W.H. Freeman and Co.; 1995.

20. Vonesh EF, Chinchilli VM, Kewel P. Goodness-of-fit in generalized nonlinear mixed-effects models. Biometrics. 1996;52:572-587.

21. Biddle SJ, Whitehead SH, O'Donovan TM, Nevill ME. Correlates of participation in physical activity for adolescent girls: A systematic review of recent literature. J Phys Act Health. 2005;2:423-434.

22. Lohman TG, Ring K, Schmitz KH, et al. Associations of body size and composition with physical activity in adolescent girls. Med Sci Sports Exerc. 2006;38(6):11751181.
23. Prochaska JJ, Rodgers MW, Sallis JF. Association of parent and peer support with adolescent physical activity. Res $Q$ Exerc Sport. 2002;73(2):206-210.

24. Saunders RP, Motl RW, Dowda M, Dishman RK, Pate RR. Comparison of social variables for understanding physical activity in adolescent girls. Am J Health Behav. 2004;28:426-436.

25. Saksvig BI, Catellier DJ, Pfeiffer K, et al. Travel by walking before and after school and physical activity among adolescent girls. Arch Pediatr Adolesc Med. 2007;161(2):153-158.

26. Brownson RC, Eyler AA, King AC, Brown DR, Shyu YL, Sallis JF. Patterns and correlates of physical activity among US women 40 years and older. Am J Public Health. 2000;90(2):264-270.

27. Epstein LH, Paluch RA, Coleman KJ, Vito D, Anderson K. Determinants of physical activity in obese children assessed by accelerometer and self-report. Med Sci Sports Exerc. 1996;28(9):1157-1164.

28. Trost SG, Pate RR, Ward DS, Saunders R, Riner W. Correlates of objectively measured physical activity in preadolescent youth. Am J Prev Med. 1999;17(2):120-126.

29. Gordon-Larsen P, Harris KM, Ward DS, Popkin BM. Acculturation and overweight-related behaviors among Hispanic immigrants to the US: the National Longitudinal Study of Adolescent Health. Soc Sci Med. 2003;57(11):2023-2034. 